\title{
Kinetics of Reduction of FeO from Slag by Graphite and Coal Chars
}

\author{
S. L. TEASDALE and P. C. HAYES \\ Pyrometallurgy Research Centre, School of Engineering, University of Queensland, Brisbane, Q 4072, Australia. \\ E-mail: P.Hayes@minmet.uq.edu.au
}

(Received on July 20, 2004; accepted on February 21, 2005)

\begin{abstract}
The rates of reduction of $\mathrm{FeO}$ from iron-saturated $\mathrm{FeO}-\mathrm{CaO}-\mathrm{Al}_{2} \mathrm{O}_{3}-\mathrm{SiO}_{2}$ slags by graphite, coke, bituminous coal and anthracitic coal chars at temperatures in the range 1673-1873 K have been measured using a sessile drop technique. The extents of reaction were determined using EPMA analysis of quenched samples, and on line gas analysis using a quadrupole mass spectrometer. The reaction rates have been shown to be dependent critically on carbon type. For the reaction geometry used in this investigation the reduction rates of graphite and coke are observed to be faster than with coal chars. This unexpected finding is shown to be associated with differences in the dominant chemical and mass transfer mechanisms occurring at the reaction interface. High reaction rates are observed to occur with the formation of liquid Fe-C alloy product and the associated gasification of carbon from the alloy. The rates of reduction by coal chars are determined principally by the chemical reaction at the carbon/gas interface and slag phase mass transfer.
\end{abstract}

KEY WORDS: slag; reduction; carbon; char; kinetics.

\section{Introduction}

In a previous paper by the authors ${ }^{1)}$ the structural and phase changes occurring during the reaction of various types of solid carbons with $\mathrm{FeO}-\mathrm{CaO}-\mathrm{Al}_{2} \mathrm{O}_{3}-\mathrm{SiO}_{2}$ slags were reported. The dominant reaction path was found to be dependent on the carbon type. It was argued that the slags are non-wetting on the carbon surfaces and reduction takes place through a gas ferrying mechanism. Following initial reaction between solid carbon and the slag $\mathrm{CO}$ gas is produced. This CO is transported through the gas phase and reacts with $\mathrm{FeO}$ in the slag to produce $\mathrm{CO}_{2}$ and metallic iron. The $\mathrm{CO}_{2}$ is transferred or ferried back to the back to the carbon, where gasification of $\mathrm{CO}_{2}$ to $\mathrm{CO}$ gas occurs. The cycle of reactions is then repeated. There are, however, significant differences in reaction path with different carbon types. In the case of slag reduction by graphite and coke the slag is partially wetting, and this facilitates the formation of a liquid $\mathrm{Fe}-\mathrm{C}$ alloy at the slag/carbon interface, providing a secondary source of carbon. The $\mathrm{CO}_{2}$ gasification reaction in this case occurs at the surface of the $\mathrm{Fe}-\mathrm{C}$ droplets. The resultant gas bubbles produced in the slag eventually become detached from the alloy and rise under bouyancy forces through the slag, increasing the mass transfer coefficient in the slag. The $\mathrm{CO}_{2}$ gasification reaction in the case of coal chars, however, occurs predominately at the solid carbon surface.

The focus of the present study is the rates of reaction between slag and a number of different carbon types, and the relationships between these rates and the observed microstructural changes. Particular emphasis is given to characterising the reaction behaviour of various types of coal char because of the increasing importance of coal injection into slags in metallurgical operations.

\section{Experimental Methods}

The $\mathrm{FeO}-\mathrm{CaO}-\mathrm{Al}_{2} \mathrm{O}_{3}-\mathrm{SiO}_{2}$ slags studied in the present investigation were prepared by melting pure oxide powders in an iron crucible under an inert gas atmosphere. Details of the procedure used in the preparation of the master slag $\left(44.2 \% \mathrm{SiO}_{2}, 38.8 \% \mathrm{CaO}, 17 \% \mathrm{Al}_{2} \mathrm{O}_{3}\right.$ by weight), and the addition of $\mathrm{FeO}$ to the slags, are provided in a previous paper by the authors. ${ }^{1)}$ The proximate analysis of the coals used in the preparation of the coal chars and the characteristics of the resulting chars are given in Table 1. The coal chars were prepared by partial combustion of samples of pulverised coals in a simulated iron blast furnace raceway. The resulting coal char powders were pressed into circular substrates approximately $2 \mathrm{~mm}$ high $\times 12 \mathrm{~mm}$ diameter.

The experiments were carried out using a sessile drop technique in which $0.15 \mathrm{~g}$ of glassy slag was placed on the pressed char substrates. The samples of slag and carbon were heated in a high purity argon atmosphere for a given time. The samples were then quenched in argon by removing them rapidly from the hot zone.

The samples were placed in a recrystallised alumina crucible and were heated in a vertical electrical resistance furnace having lanthanum chromite heating elements. The reaction tubes used were $20 \mathrm{~mm}$ ID recrystallised alumina. Water-cooled coils were wound around both ends of the reaction tube, and the furnace ends were sealed with rubber O-rings. An alumina stand supported on an alumina thermocouple sheath was inserted from the bottom of the reac- 
Table 1. Coal and char characteristics.

\begin{tabular}{|c|c|c|c|c|c|c|}
\hline & \multicolumn{6}{|c|}{ CHAR NUMBER } \\
\hline & 14 & 18 & 20 & 21 & 28 & 39 \\
\hline \multicolumn{7}{|c|}{ CHAR ANALYSIS (air dried basis chars 20,21, 28, 39; dry basis chars 14,18 ) } \\
\hline Moisture (\%) & 1.38 & 2.0 & 2.3 & 1.7 & 3.9 & 2.0 \\
\hline Ash (\%) & 20.06 & 9.73 & 5.9 & 9.6 & 18.4 & 17.3 \\
\hline Volatiles (\%) & 1.10 & $?$ & 5.8 & 1.3 & 5.7 & 3.6 \\
\hline Fractional burnout in PCI & 0.49 & 0.32 & 0.1 & 0.26 & 0.41 & 0.59 \\
\hline $\begin{array}{l}\text { Specific reaction rate }(\mathrm{g} / \mathrm{g} / \mathrm{s} \mathrm{x} \\
\left.10^{-6}\right) 1673 \mathrm{~K} 0.038 \mathrm{~atm} \mathrm{CO} 2\end{array}$ & 22.9 & 38.9 & 46.0 & 6.1 & - & 95.7 \\
\hline $\begin{array}{l}\text { Intrinsic reactivity }\left(\mathrm{g} \mathrm{m}^{2} \mathrm{~s}^{-1} \mathrm{x}\right. \\
\left.10^{-8}\right), 1673 \mathrm{~K} 0.038 \mathrm{~atm} \mathrm{CO}_{2}\end{array}$ & 2.2 & 3.0 & 1.1 & 10 & - & 3.9 \\
\hline \multicolumn{7}{|l|}{ COAL ANALYSIS } \\
\hline \multicolumn{7}{|c|}{ PROXIMATE ANALYSIS (air dried basis) } \\
\hline Moisture (\%ad) & 1.5 & 2.0 & 1.8 & 1.9 & 2.8 & 2.8 \\
\hline Ash (\%ad) & 11.2 & 7.3 & 5.6 & 7.6 & 12.2 & 7.9 \\
\hline Volatile Matter & 16.2 & 20.9 & 6.8 & 12.8 & 30.6 & 32.7 \\
\hline Fixed Carbon (\%ad) & 71.1 & 69.8 & 85.8 & 77.7 & 54.4 & 56.6 \\
\hline \multicolumn{7}{|c|}{ ULTIMATE ANALYSIS (dry basis) } \\
\hline Carbon (\%daf) & 89.9 & 88.91 & 93.49 & 91.09 & 84.53 & 85.46 \\
\hline Hydr & 4.63 & 4.58 & 3.10 & 4.03 & 5.58 & 5.5 \\
\hline Nitrogen & 2.03 & 1.73 & 1.73 & 1.65 & 2.10 & 1.98 \\
\hline $\begin{array}{l}\text { Oxygen (by difference, } \\
\text { including errors) }\end{array}$ & 2.72 & 4.3 & 0.93 & 2.65 & 7.14 & 6.69 \\
\hline Total Sulphur (\%daf) & 0.72 & 0.48 & 0.75 & 0.58 & 0.65 & 0.37 \\
\hline \multicolumn{7}{|l|}{ ASH ANALYSIS } \\
\hline Silicon as oxide $(\%$ & 55.5 & 46.0 & 50.1 & 42.0 & 53.2 & 48.0 \\
\hline Alu & 28.3 & 37.3 & 30.9 & 37.0 & 38.4 & 29.7 \\
\hline Iron & 5.8 & 8.2 & 5.0 & 9.9 & 2.2 & 8.4 \\
\hline Calcium as oxide (\%) & 2.8 & 2.6 & 3.9 & 2.0 & 0.93 & 4.8 \\
\hline Magnesium as oxide (\%) & 0.79 & 1.0 & 0.93 & 0.58 & 0.35 & 1.1 \\
\hline Manganese as oxide (\%) & 0.10 & $<0.02$ & 0.04 & 0.07 & $<0.02$ & 0.03 \\
\hline Potassium as oxide (\%) & 0.93 & 0.3 & 1.0 & 1.5 & 0.89 & 1.4 \\
\hline Sodiu & 0.51 & 0.1 & 1.6 & 0.81 & 0.29 & 0.36 \\
\hline Titani & 1.60 & 1.9 & 1.7 & 2.3 & 1. & 1.6 \\
\hline Phosphorus as oxide (\%) & 1.34 & 1.61 & 1.68 & 1.43 & 0.6 & 1.52 \\
\hline Sulphur as oxide (\%) & 0.59 & 0.26 & 1.4 & 0.88 & 0.28 & 2.5 \\
\hline Zinc as oxide (\%) & $\mathrm{n} / \mathrm{a}$ & 0.03 & 0.03 & 0.03 & 0.03 & $<0.02$ \\
\hline \multicolumn{7}{|l|}{ ASH FUSION (REDUCING) } \\
\hline Deformation Temperature $(\mathrm{K})$ & 1593 & $>1823$ & 1533 & $>1823$ & 1793 & 1563 \\
\hline Spheri & 1813 & $>1823$ & 1743 & $>1823$ & $>1823$ & 1723 \\
\hline Hemispherical Temp $(\mathrm{K})$ & 1823 & $>1823$ & 1783 & $>1823$ & $>1823$ & 1733 \\
\hline Flow Temperature $(\mathrm{K})$ & 1823 & $>1823$ & $>1823$ & $>1823$ & $>1823$ & 1763 \\
\hline \multicolumn{7}{|l|}{ MISCELLANEOUS ANALYSIS } \\
\hline Sulphur $(\%$, ad $)$ & 0.63 & 0.44 & 0.69 & 0.53 & 0.56 & 0.33 \\
\hline Vitrinite reflectar & 1.71 & 1.22 & 3.17 & 1.92 & 0.91 & 0.77 \\
\hline Specific energy (MJ/kg) & 31.51 & 32.61 & 33.10 & 32.64 & 29.87 & 31.21 \\
\hline
\end{tabular}

tion tube, and this stand could be moved from the base of the reaction tube into the hot zone. The hot zone length is approximately $80 \mathrm{~mm}$, over which the temperature varies by $\pm 2 \mathrm{~K}$.

The extents of reaction in the slag samples were measured by two methods, i) electron probe X-ray microanalysis (EPMA) of quenched slag samples, and ii) on line quadrupole mass spectrometer measurements (QMS) of the resulting gas composition and mass flows. ${ }^{2}$

\subsection{EPMA}

The quenched slag samples were mounted and polished cross sections were examined using scanning electron microscope (SEM) and electron probe X-ray microanalysis (EPMA) with wavelength dispersive spectrometers. The quenched silicate slags formed glass on cooling from the furnace to room temperature enabling the iron oxide concentrations within the slag phase to be accurately measured at various positions within the cross section. The mean $\mathrm{FeO}$ concentrations reported in this study are obtained from measurements across the whole section of the sample.

\subsection{On Line Gas Analysis Using a Mass Spectrometer}

Figure 1 shows the sample geometry, and a schematic of the furnace-quadrupole mass spectrometer (QMS) facility

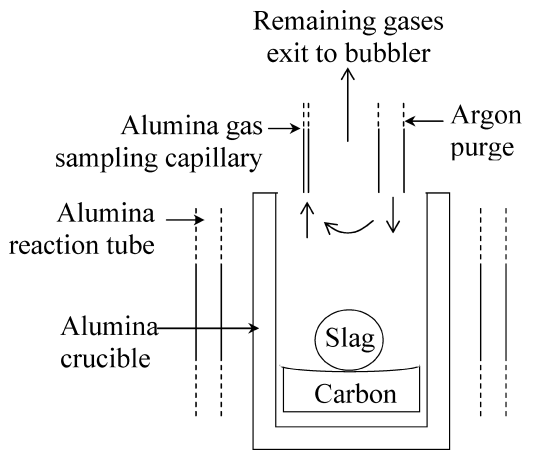

Fig. 1. Schematic of the carbon substrate and the slag droplet inside the reaction tube.

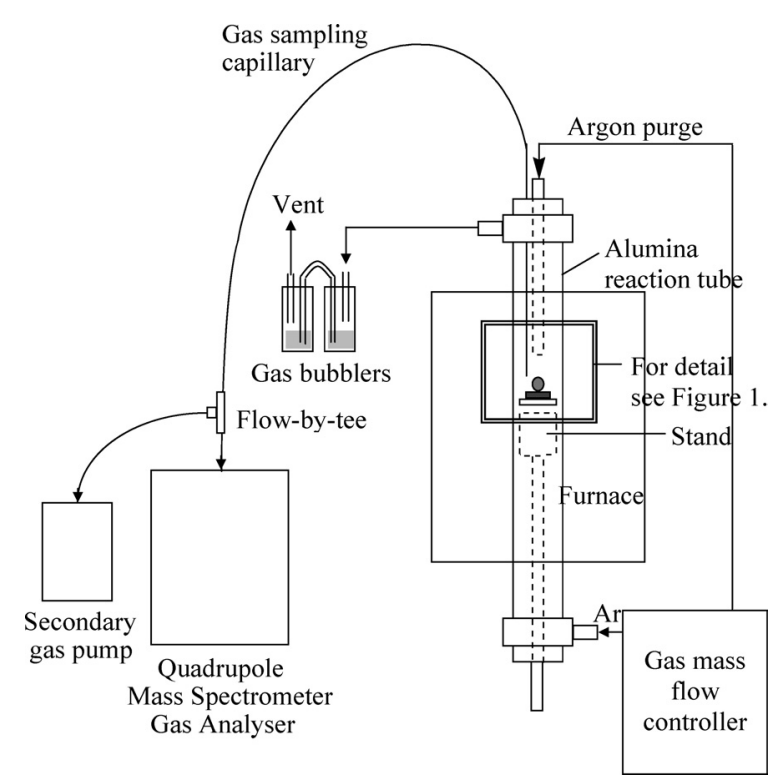

Fig. 2. Schematic of the quadrupole mass spectrometer-furnace assembly used for kinetic tests.

is shown in Fig. 2. A gas mass flow controller is used to introduce ultra high purity argon gas $(99.999 \%)$ at a known rate into the reaction tube. The argon inlet tube is positioned close to and above the sample to provide a continuous gas flow across the surface of the slag sample. A gas sampling capillary is positioned at the mouth of the crucible; this enables the reaction gases to be extracted from the reaction site for analysis by the mass spectrometer. The gas flow, the configurations and dimensions of the various tubes were selected so as to ensure laminar plug flow of the product gases into the sampling capillary and to provide a fast, reproducible response to changes in gas composition. This was confirmed by injecting tracer gas "spikes" in the gas lines. The resulting peaks that were detected by the mass spectrometer decayed over a period of only $2 \mathrm{~s}$. The remaining gases, those not drawn into the sampling capillary, move up through the furnace tube and exit through the top outlet and through a n-di-butyl-phthalate bubbler to maintain an ambient pressure close to one atmosphere.

Since $\mathrm{CO}$ and $\mathrm{N}_{2}$ have identical amu values, it was important to eliminate nitrogen from the system to enable the accurate measurement of $\mathrm{CO}$ with the QMS; all the connections from the gas bottles, to the mass flow controller, to the furnace, and to the mass spectrometer were therefore tightly 
sealed from the atmosphere. For the experiments, the scanned mass range was limited to $18,28-36$, and $44 \mathrm{amu}$. This enabled the monitoring of the relevant peaks for $\mathrm{H}_{2} \mathrm{O}$ (18), $\mathrm{N}_{2} / \mathrm{CO}(28), \mathrm{O}_{2}$ (32), $\mathrm{Ar}(36)$, and $\mathrm{CO}_{2}$ (44). The larger argon peaks at $20 \mathrm{amu}$ and $40 \mathrm{amu}$ were not scanned. This meant that a higher multiplier gain could be used to accentuate the smaller peaks, whilst avoiding damage to the multiplier with off-scale voltages. The argon 36 peak was chosen to represent argon since it had a comparable intensity to the $\mathrm{CO}$ and $\mathrm{CO}_{2}$ peaks. Each time the filament was switched on, the mass spectrometer was calibrated for the sensitivities of $\mathrm{CO}$ and $\mathrm{CO}_{2}$ with respect to argon using standard gas mixtures.

The output from the QMS data processing software is a spectrum with a series of peaks representing detected ions. The concentrations of the gas species were determined by comparison of the maximum peak intensities obtained for selected peaks with the intensities obtained from standard samples of known concentration. ${ }^{2)}$

\subsection{Procedure for Kinetic Experiments}

$0.15 \mathrm{~g}$ of glassy slag is placed on top of the carbon substrate within the alumina crucible. This is inserted into the furnace, positioned at the water cooled end at a temperature of about $393 \mathrm{~K}$. The furnace is then purged with argon from both the top and bottom gas inlets until the air concentration is less than 40 ppm.

Before raising the crucible and stand inside the furnace, the argon purge rate is adjusted to a rate of $530 \mathrm{~mL} / \mathrm{min}$ (STP) from the top purge tube and $200 \mathrm{~mL} / \mathrm{min}$ from the bottom gas inlet. The crucible is slowly moved to a point $130 \mathrm{~mm}$ below the reaction site, at a temperature of about $1173 \mathrm{~K}$. The sample is held for approximately $5 \mathrm{~min}$ to allow time for the residual gas to be removed from the sample. Although this temperature is below the slag solidus, the glassy slag is able to soften and agglomerate, before starting to slowly crystallise. Nevertheless, in the short time period before the sample is inserted into the hot zone, only a small amount of solids formation occurs in the slag, and any slag-carbon reaction is insignificant.

The crucible is raised the remaining $130 \mathrm{~mm}$ into the hot zone, and the bottom purge is immediately switched off. The concentrations of argon and the reaction gases are continuously monitored as the reaction proceeds. At the end of the reaction period, the stand is slowly lowered from the hot zone, avoiding excessive disruption of the sample. Argon is again purged through the inlet at the bottom of the reaction tube to dilute any air build-up under the stand. After the crucible is cooled to below $473 \mathrm{~K}$, it is removed from the furnace.

\subsection{Char Pre-treatment}

It was found in preliminary experiments that on reheating the chars to the reaction temperature considerable quantities of $\mathrm{CO}$ and $\mathrm{CO}_{2}$ gases are released (Fig. 3). The volumes of these and other adsorbed gases in the carbon pellets can be greater than the total volume of gas produced during reduction of the slags. In the present studies the effect is particularly significant in the case of the char samples since the mass of carbon is high relative to that of the slag.

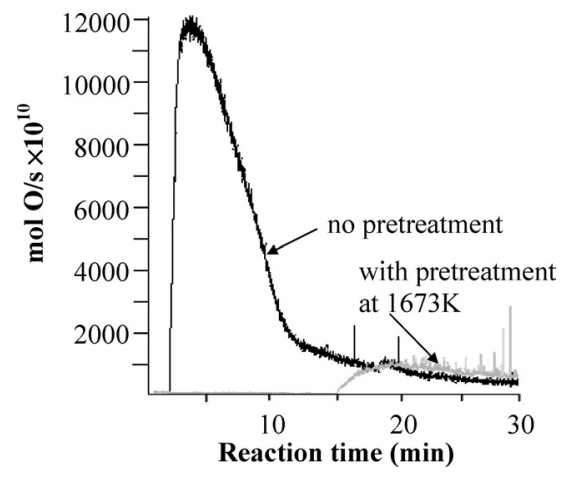

Fig. 3. The effect of thermal pretreatment of the char pellets at $1673 \mathrm{~K}$ on gas evolution from slag/carbon reactions.

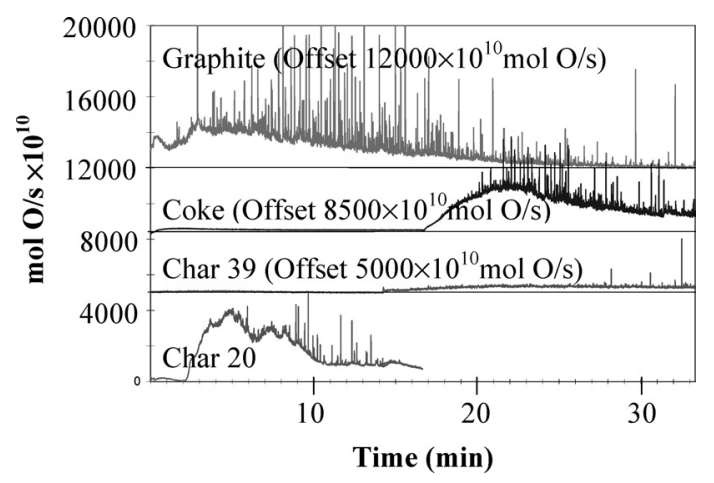

Fig. 4. Examples of rate-time plots obtained using on line QMS measurements, showing typical oxygen release rates resulting from slag reduction by graphite, coke, char 39 and char 20 at $1673 \mathrm{~K}$; initial slag $10.8 \mathrm{wt} \% \mathrm{FeO}$.

To enable the slag/char reaction to be measured using the QMS and to avoid reduction of the slag during pretreatment it was necessary to use a two-stage treatment. The char pellet on its own was treated to remove the adsorbed species by heating to $1673 \mathrm{~K}$ for $4 \mathrm{~h}$ in ultra high purity argon, or until no more gases were released, then cooled to below $523 \mathrm{~K}$ before it was removed from the furnace. Solid slag was then placed on the char as for the graphite and coke runs, and inserted into the hot zone after the furnace was purged. The procedure outlined in the previous section was then followed. Blank char runs with no slag demonstrated that there were almost no adsorbed gases remaining on the chars prior to the slag reduction stage of the experiments. This observation supports previous reports ${ }^{5)}$ that the oxides that adsorb on exposed carbon surfaces below $473 \mathrm{~K}$ desorb at temperatures below $973 \mathrm{~K}$.

\section{Results}

Examples of the rates of reduction of slag as a function of time at $1673 \mathrm{~K}$ measured using the QMS are presented in Fig. 4 for graphite, coke and coal chars and slags containing initially $10.5 \mathrm{wt} \% \mathrm{FeO}$. The rates are deduced from the $\mathrm{CO}$ and $\mathrm{CO}_{2}$ gas volumes measured using the quadrupole mass spectrometer, assuming the oxygen is removed as $\mathrm{CO}$ and $\mathrm{CO}_{2}$, i.e. $R_{\mathrm{o}}\left(\mathrm{mol} \mathrm{O} \mathrm{s}^{-1}\right)=\left(\left[\mathrm{CO} \mathrm{mL} \mathrm{s}{ }^{-1}\right)+2\left[\mathrm{CO}_{2}\right.\right.$ $\left.\left.\mathrm{mL} \mathrm{s}^{-1}\right]\right) / 22414$. Note that in Fig. 4 the rate scales have been offset for clarity by the amounts indicated. There are a number of general features about the rate curves in Fig. 4 that require further explanation. 
- The incubation period

- The overall shapes of the curves

- The presence of periodic rate maxima imposed on the rate curves.

These issues are discussed further in the following sections. The reproducibility of the graphite/slag and coke/slag rate/time responses is very good. The char/slag samples do not produce the same level of reproducibility, nevertheless, the reproducibility of the measurements was sufficient to distinguish the differing behaviours of the various chars tested.

\subsection{The Incubation Period}

Gas release is observed from the graphite-slag reaction as soon as the slag becomes molten. In the case of coke and chars, significant delays ranging in duration from 0 to 30 min have been observed in the present experiments before the reaction proceeds. It will be recalled ${ }^{1)}$ that high temperature pretreatment of all of the carbons is undertaken in order to remove adsorbed $\mathrm{CO}$ and $\mathrm{CO}_{2}$ gases from the carbon surfaces. Although performed under high purity argon gas this pretreatment results in some oxidation of the carbon surface exposing the mineral matter in the carbon. Pellets that were not pretreated, or had the ash layer on top of the pellet removed after pretreatment, did not generate exhibit incubation periods.

For the purpose of the presentation of the kinetic data in the present study, the zero time of the reaction is taken as the time at which gas release is first detected with the mass spectrometer rather than the time at which the sample is introduced into the hot zone.

\subsection{The Overall Shapes of the Curves}

In all cases the reaction rate increases to a maximum value, then decreases with reaction time. The time taken to reach the maximum rate varies with carbon type. For a given slag mass the magnitude of the maximum rate decreases generally in the order graphite, coke, anthracite char and bituminous coal char; the time to reach the maximum rate increases is in the same order.

\subsection{The Presence of Periodic Rate Maxima}

Superimposed on the general shape of the reaction rate curves are periodic rate maxima each of which occur over a short time frame - a matter of seconds, giving the appearance of sharp peaks superimposed on the curves. These maxima are observed to occur at high frequency from almost the start of the reactions in the case of graphite, but only infrequently and after long periods from the start of reaction in the case of the chars, e.g. bituminous coal char 39. These periodic maxima are not artifacts of the measurement technique; they are one to two orders of magnitude greater than the signal background noise.

\subsection{Extents of $\mathrm{FeO}$ Reduction}

The extents of reduction of $\mathrm{FeO}$ from graphite/slag, coke/slag, char/slag and anthracite char/slag reactions at $1673 \mathrm{~K}$, as determined from EPMA measurements of the slag composition and integrated $\mathrm{CO}$ and $\mathrm{CO}_{2}$ gas release data from QMS measurements, are presented as points in Fig. 5. The results obtained for graphite and coke samples

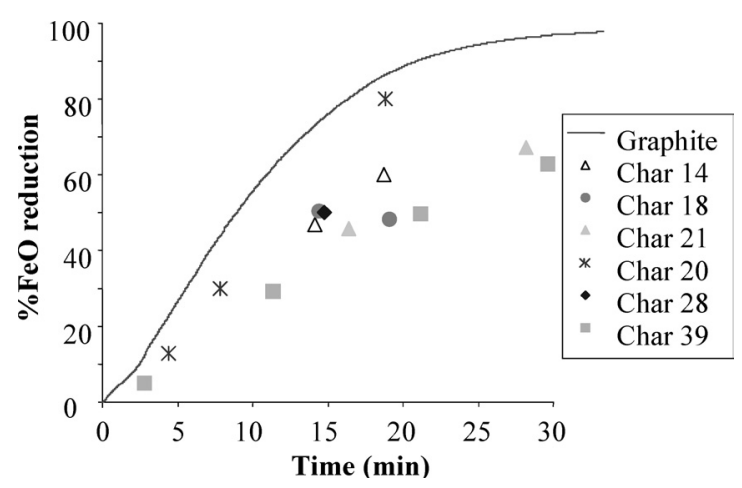

Fig. 5. \%FeO reduction $v s$. time of slag measured by EPMA analysis of quenched samples at $1673 \mathrm{~K}$. (Initial slag $10.8 \mathrm{wt} \% \mathrm{FeO})$.

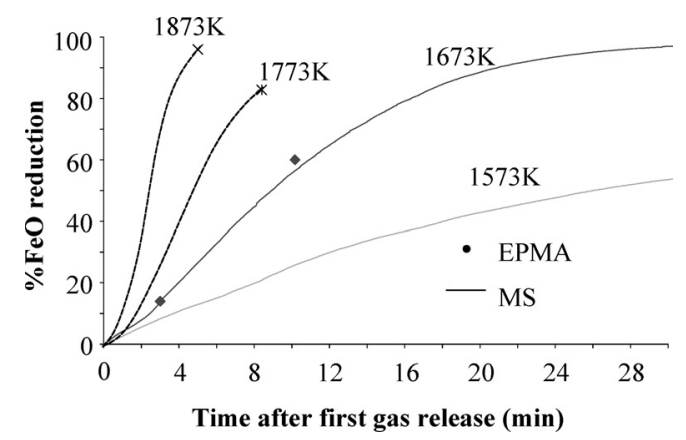

Fig. 6. Comparison of $\% \mathrm{FeO}$ reduction vs. time with graphite as determined by EPMA and mass spectrometer (MS) (1 573-1 $873 \mathrm{~K}$; initial slag $10.8 \mathrm{wt} \% \mathrm{FeO}$ ).

are identical within experimental uncertainty. For the graphite/slag and coke/slag tests, the extents of reaction measured by slag analysis agree well with the values derived from mass spectrometry measurements of the rates of evolution of $\mathrm{CO}$ and $\mathrm{CO}_{2}$. For the char/slag tests, however, the extents of oxygen removal calculated from the gas release as measured by the mass spectrometer are lower than that determined from the slag $\mathrm{FeO}$ analysis. The reason for this difference between the EPMA and QMS techniques in these cases will be discussed in detail elsewhere in the paper and correction factors have been applied to the QMS data to take into account these differences.

It is clear that the overall rates of reduction with graphite and coke are faster than with coal chars although these rates are approached with anthracite char. This is an unexpected result and the reasons for this will be discussed later in the paper.

The effect of temperature on the rates of reduction of $\mathrm{FeO}$ from slag by graphite and char 39 at $1573 \mathrm{~K}, 1673 \mathrm{~K}$, $1773 \mathrm{~K}$ and $1873 \mathrm{~K}$ are shown in Figs. 6 and 7 respectively. Clearly the rate of reduction increases with increasing reaction temperature. The apparent activation energies for reduction for graphite and char 39 are almost identical in the range of 158 to $170 \mathrm{~kJ} \mathrm{~mol}^{-1} \mathrm{~K}^{-1}$. Note however that the reaction rates between slag and char 39 at $1573 \mathrm{~K}$ $\left(1300^{\circ} \mathrm{C}\right)$ are significantly slower than at the other temperatures and appear to be approaching zero as time proceeds; metallographic inspection of the cross section of the interface between carbon and slag in these samples shows the formation of a solid ferritic iron layer at this temperature.

Figure 8 shows the change in bulk concentration of $\mathrm{FeO}$ 


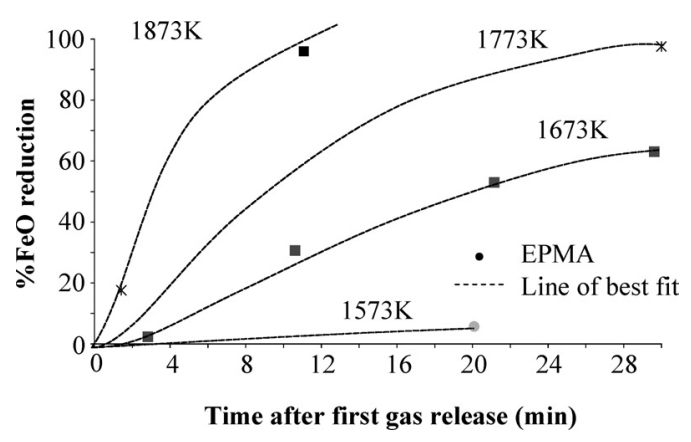

Fig. 7. Comparison of \% reduction of $\mathrm{FeO} v s$. time with char 39 as determined by EPMA (1573-1873 K; initial slag $10.8 \mathrm{wt} \% \mathrm{FeO})$.

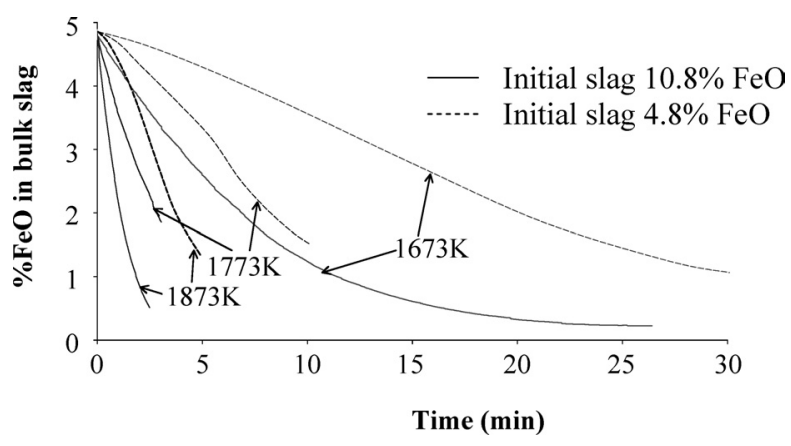

Fig. 8. Comparison of reduction rates with graphite, for initial slags containing $4.8 \% \mathrm{FeO}$ and $10.8 \% \mathrm{FeO}$.

with time for slags of different starting compositions of 10.8 and $4.8 \% \mathrm{FeO}$ reduced with graphite. It can be seen that for each of the temperatures $1673 \mathrm{~K}, 1773 \mathrm{~K}$ and $1873 \mathrm{~K}$ the rates of reduction of the slags that started from the higher initial $\mathrm{FeO}$ concentration are greater than for the same bulk composition that contained a lower initial $\mathrm{FeO}$ concentration. In other words the reduction behaviour is dependent in some way on the reduction history. This phenomenon has not been previously reported for this reaction system and appears to be most unusual.

\subsection{The Influence of Metallic Iron}

Since the initial slags are prepared under metallic iron saturation conditions the extent of reduction is related directly to the formation of metallic iron. The effect of iron metal on the reaction rate has been further investigated by adding fine particles of $\mathrm{Fe}-\mathrm{C}$ alloy to the slag/carbon interface prior to the experiment. $0.01 \mathrm{~g}$ of carbon-saturated iron filings was added in each case. The quantity of carbon originally present in the $\mathrm{Fe}-\mathrm{C}$ filings is sufficient to reduce the $\mathrm{FeO}$ from the slag droplet from $10.8 \% \mathrm{FeO}$ to $9 \% \mathrm{FeO}$, and $4.8 \% \mathrm{FeO}$ to $3.0 \% \mathrm{FeO}$, assuming all of this carbon is consumed. The balance of the carbon required for reduction must come from the solid carbon material, as in previous experiments.

The integrated gas release plots, showing extents of $\mathrm{FeO}$ reduction as a function of time for all samples tested with $10.8 \% \mathrm{FeO}$ slag are presented in Fig. 9. Here it is shown clearly that, whilst the addition of $\mathrm{Fe}-\mathrm{C}$ alloys are able to accelerate the graphite/slag reaction, the addition of $\mathrm{Fe}-\mathrm{C}$ alloys to chars tends to reduce the reaction rates, once the carbon is consumed from the alloy. Examination of the rate

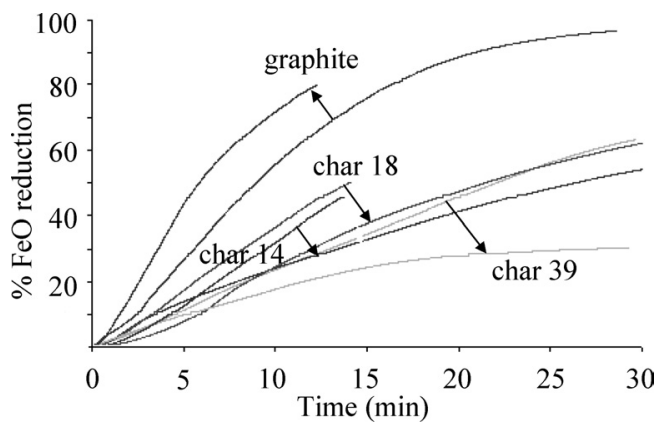

Fig. 9. \% reduction $v s$. time for slags reduced with and without $\mathrm{Fe}-\mathrm{C}$ additions (initial slag $10.8 \mathrm{wt} \% \mathrm{FeO}, 1673 \mathrm{~K}$ ). The head of the arrow in each case indicates the complementary experiment in which $\mathrm{Fe}-\mathrm{C}$ alloy is used to dope the carbon substrate.

data reveals that when the slag contains $4.8 \% \mathrm{FeO}$, the addition of $\mathrm{Fe}-\mathrm{C}$ alloys to chars has at best no effect on the reaction rates, after the carbon is consumed from the alloy.

\section{Discussion}

\subsection{Incubation Period}

During pretreatment of the carbons to remove adsorbed $\mathrm{CO}$ and $\mathrm{CO}_{2}$ gas species partial oxidation of the carbon surface occurs. In the cases of coke and coal chars this pretreatment exposes the mineral matter or ash present in these carbons; the graphite contains no mineral matter. It is argued that the state of the ash layer can have major implications on the reaction kinetics. Assuming the reaction proceeds through the gas ferrying mechanism between the char/gas and slag/gas interfaces, then physical or direct contact between carbon and slag is not necessary for reaction to proceed. If there is a porous ash layer over the surface of the char, then the $\mathrm{CO}$ reductant and $\mathrm{CO}_{2}$ product gases can diffuse through this ash layer. A partially or fully fused ash layer on the carbon can inhibit, and even prevent, gas penetration; in this scenario the reaction may only proceed when the ash is removed by dissolution into the liquid slag.

The ash composition and ash fusion characteristics in reducing gas mixtures $\left(\mathrm{CO}_{2} / \mathrm{H}_{2}=1\right)$ are provided in Table 1 . Char 14, char 20, and char 39 have ash deformation temperatures under reducing conditions that are below $1573 \mathrm{~K}$. The ash surface covering the char pellet will thus be partially liquid and can sinter during the $1673 \mathrm{~K}$ pretreatment (see Fig. 10). Both char 18 and char 28 are reported to have ash deformation temperatures above $1773 \mathrm{~K}$, yet still exhibit substantial incubation periods. Examination of the char surfaces in these cases shows that nevertheless partial fusion of the ash particles has occurred (see Fig. 11). Char 21 on the other hand also has a high ash deformation temperature under reducing conditions $>1823 \mathrm{~K}$, indicating that the ash is solid at $1673 \mathrm{~K}$. In this case a powdery porous ash deposit was formed and no incubation period was observed before the start of reaction. It was also observed, as stated previously in Sec. 3.1, that char pellets that were not pretreated, or had the ash layers on top of the pellet removed after pretreatment, did not exhibit incubation periods. All of these observations support the argument that, in the present experiments, the formation of sintered ash layers is respon- 


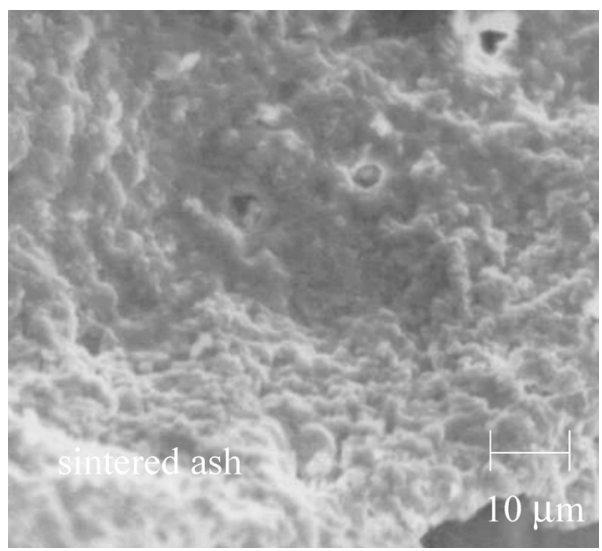

Fig. 10. SEM image of sintered ash layer formed on the surface of a char 14 pellet after thermal pretreatment at $1673 \mathrm{~K}$.

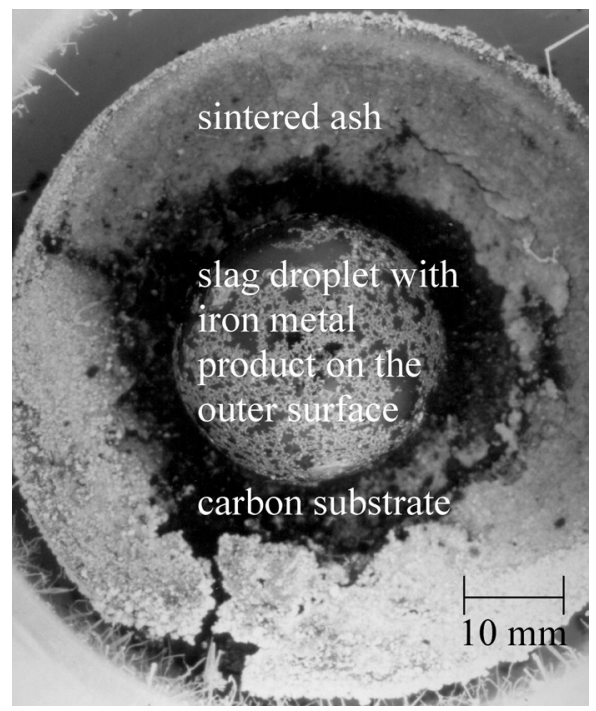

Fig. 11. SEM micrograph of char 28 after reaction with $10.8 \%$ $\mathrm{FeO}$ slag at $1673 \mathrm{~K}$. The sintered ash layer forms a brittle crust over the char surface.

sible for the observed incubation times before the start of slag reduction.

\subsection{Comparison of QMS and EPMA Data}

Comparisons of the cumulative oxygen removed from the slag provided by the mass spectrometer and the EPMA measurements for the graphite/slag and coke/slag reactions showed good agreement. However, in the case of the experiments using chars the actual extents of reduction in the slag measured by EPMA are greater than those determined from the analysis of gases using the mass spectrometer. The differences in the data obtained from the two methods appear to be dependent on char type and the quantity of $\mathrm{FeO}$ reduced, the maximum differences occurring at the start of the reactions.

It was shown in Fig. 3 that high temperature thermal pretreatment in high purity $\mathrm{Ar}$ (low pCO, low $\mathrm{pCO}_{2}$ ) was necessary to remove adsorbed $\mathrm{CO}$ and $\mathrm{CO}_{2}$ gas species from the surfaces of the char following preparation by partial combustion of coal. During reaction with the slag the pCO at the char/gas interface is increased and, it is argued, some of the product $\mathrm{CO}$ gas is selectively adsorbed on the char substrate, establishing local equilibrium between the gas and adsorbed species. This adsorbed gas does not therefore exit the crucible, and is not therefore measured by the QMS.

The adsorption of $\mathrm{CO}$ by the char during the reduction reaction was demonstrated in the following experiments. Pretreated substrates of char 18 and char 14 were partially reacted with slag at $1673 \mathrm{~K}$, and then furnace cooled in high purity argon. The partially reacted slag droplets were then removed from the char surface, the reaction tube was resealed, flushed with high purity argon and the substrate in the same alumina crucible were reintroduced to into the hot zone at $1673 \mathrm{~K}$. High purity argon gas was passed over the samples and the resulting gas environment around the char substrates was continuously sampled and monitored for $\mathrm{CO}$ and $\mathrm{CO}_{2}$ using the QMS. Significant quantities of $\mathrm{CO}$ were released from char 18 and char 14 substrates. The quantities of oxygen released in this post treatment were sufficient to account for approximately one third of the differences between the EPMA and the "on line" QMS measurements.

It is argued that the differences in the extents of gas adsorption between the various carbons may be explained by differences in surface area and characteristics of the carbon surfaces in each case. ${ }^{4-9)}$ In the present study the EPMA measurements of the slag compositions provide more accurate data on the extent of reduction. The QMS data quoted in this study have been corrected by factors that make the mean EPMA and QMS data compatible.

\subsection{Reaction Rates and Mechanisms}

The measurements clearly demonstrate that the following factors are important in determining to the rates of reduction of FeO-containing slags with carbon,

- Carbon type,

- FeO concentration of the slag,

- Temperature

- The amount of iron present at the reaction interface.

- The reaction mechanisms that are operating.

\subsection{Graphite/Slag Reaction}

In the previous study ${ }^{1)}$ of this system and reaction geometry metallographic evidence was produced that demonstrate, for samples in which graphite and coke were used as reductant, gas bubbles were found to be present within the slag phase at all stages of the reduction and appeared to be associated with $\mathrm{Fe}-\mathrm{C}$ droplets. "In situ" observations using $\mathrm{X}$-ray transmission images also confirmed this phenomenon. The significance of the periodic maxima or sharp peaks in reaction rate that are measured using the QMS, reported in Fig. 1, now becomes clear. Each of these peaks is associated with the bursting of a bubble at the surface of the slag, releasing a packet of reaction product gas to the mass spectrometer detector. The bubble release from the slag sample thus represents the contribution of the gas generated from the reaction with the $\mathrm{Fe}-\mathrm{C}$ droplets rather than from the solid carbon/slag interface.

The overall rates of oxygen removal from the slags by reduction with graphite and coke come through contributions from reaction mechanisms occurring at the graphite/slag and $\mathrm{Fe}-\mathrm{C}$ alloy/slag interfaces.

The rates of removal of oxygen from slags at $1673 \mathrm{~K}$ for different $\mathrm{FeO}$ concentrations and with varying quantities of 


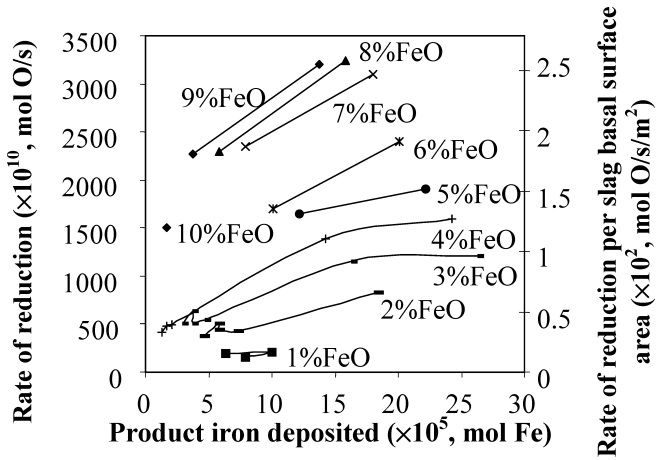

Fig. 12. The relationship between the graphite/slag reaction rate at $1673 \mathrm{~K}$ and the amount of iron present at the graphite/slag interface for different $\mathrm{FeO}$ concentrations in the slag.

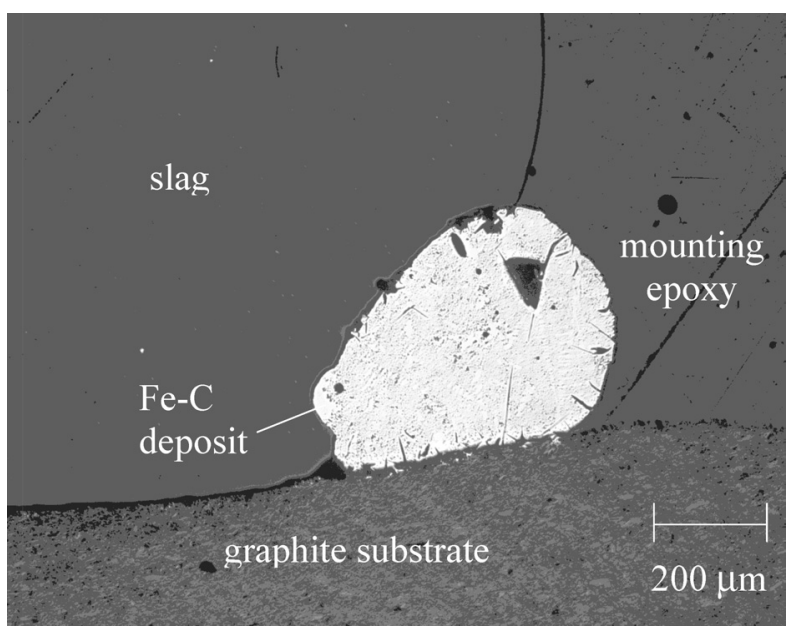

Fig. 13. Optical micrograph of sample cross section after reduction of $10.8 \% \mathrm{FeO}$ slag down to $2.2 \% \mathrm{FeO}$ by $\mathrm{Fe}-\mathrm{C}$ doped graphite. $\mathrm{Fe}-\mathrm{C}$ deposit has a hypereutectic grey iron microstructure, indicating a carbon concentration $>4.3 \%$.

iron deposited at the graphite interface are given in Fig. 12. This shows that the reaction rates with graphite are progressively increased as the mass of iron deposited at the graphite/slag interface increases. These observations support the view that significant contributions to the overall rate of reduction of the slag occurs through the $\mathrm{Fe}-\mathrm{C}$ reduction mechanism.

It is well established that the chemical reaction rate of the carbon gasification reaction on the surface of metallic iron is fast compared to the intrinsic reactivities of solid carbons. ${ }^{10)}$ It follows that, provided the carbon can rapidly dissolve in the iron, the presence of relatively small quantities of iron metal droplets at the interface can increase the overall reaction kinetics.

Observations of the composition of $\mathrm{Fe}-\mathrm{C}$ alloy formed at the graphite/slag interfaces (Fig. 13) clearly indicate that the dissolution of carbon in liquid iron from the graphite is rapid compared to the rate of consumption by gasification.

The iron formed at the graphite/slag interface appears to be retained at that interface. The reason for this has yet to be clearly established, however, it may be related to the wetting characteristics of the carbon by the slag.

Another feature of the reduction behaviour with graphite and coke is that the formation of gas bubbles occurs at the site of the Fe-C alloy droplets. The gas bubbles then become detached and move up through the slag under buoyancy forces, mixing the slag as they go. This phenomenon is demonstrated by metallographic evidence and EPMA measurements of the quenched samples presented in the previous investigation. ${ }^{1)}$ At high $\mathrm{FeO}$ concentrations in the slag with graphite reductant there are no $\mathrm{FeO}$ concentration gradients in the slag $\mathrm{FeO}$ concentration profiles at the slag/carbon interface only observed at bulk FeO concentrations less than $5 \%$. Significant $\mathrm{FeO}$ concentration profiles at the reaction interface suggest that the reaction rates at these low solute concentrations become limited by mass transfer in the slag phase from the bulk slag to the reduction sites at the graphite/slag and $\mathrm{Fe}-\mathrm{C}$ alloy/slag interfaces.

\subsection{Char/Slag Reaction}

It was shown in the previous study ${ }^{1)}$ that, in general, coal chars used are poorly wet by $\mathrm{FeO}-\mathrm{CaO}-\mathrm{Al}_{2} \mathrm{O}_{3}-\mathrm{SiO}_{2}$ slags, e.g. the contact angle between carbon and slag approaches $170^{\circ}$. The evidence suggests that the wetting characteristics have a significant effect on the dominant reduction mechanism taking place with these samples. It appears that the metallic iron nuclei formed initially in the slag at the carbon/slag interface are transferred away from this interface to the external free surface of the slag. How this transfer takes place is still to be demonstrated categorically but it could be the result of fluid flow induced by surface tension forces (Marangoni flow). Since the iron particles have been removed from contact with the solid carbon the reduction of the slag takes place predominantly through the gasification and gas ferrying mechanisms occurring at the char/slag interface.

The presence of periodic rate maxima in the QMS reaction rate measurements with chars show that only in the later stages in reduction do significant quantities of metallic iron accumulate at the char/slag interface and contribute to reduction through the $\mathrm{Fe}-\mathrm{C}$ alloy. The evidence indicates that the rates of carbon dissolution in iron from the char are slow. In the reaction systems investigated in the present study at high $\mathrm{FeO}$ concentrations in the slag the rate of gasification of the carbon from the metallic iron into the gas phase exceeds the rate at which carbon is supplied by the char. Much of the iron therefore remains at a low carbon concentrations and therefore solid at $1673 \mathrm{~K}$ (Fig. 14). Some liquid iron droplets are formed at the later stages of reduction when the $\mathrm{FeO}$ concentration in the slag is lowered. At these low $\mathrm{FeO}$ concentrations it is argued that the rate of carbon removal by reaction with slag would become progressively slower compared to the rate of carbon dissolution into the iron, hence a gradual build up in the carbon concentration in the iron at the interface, leading eventually to melting of the alloy.

It was reported in ${ }^{1)}$ that the contact angle is dependent on carbon type, and as a result the contact area between slag and carbon for the same mass of slag will depend on carbon type. The basal contact areas between graphite/coke and slag are approximately three to four times greater than for the char/slag depending on slag composition and temperature. This factor should be taken into account when considering the relative contributions of the various reaction 


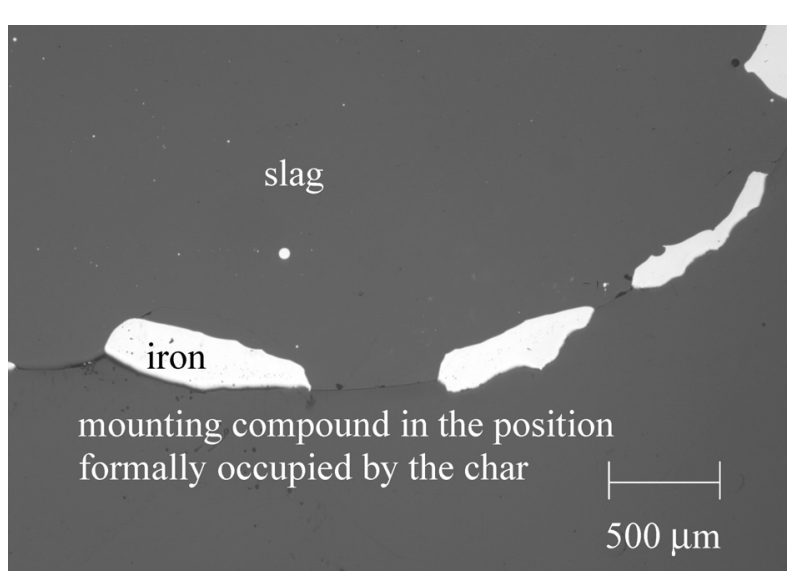

Fig. 14. Optical micrograph of sample cross section after reduction of $10.8 \% \mathrm{FeO}$ slag down to $7.4 \% \mathrm{FeO}$ by char 39 and with $\mathrm{Fe}-\mathrm{C}$ alloy addition at $1673 \mathrm{~K}$.

mechanisms to the overall oxygen removal.

The $\mathrm{CO}_{2}$ reactivities of the chars used in the present investigation were measured using an established technique developed to measure the intrinsic reaction rate, the reaction order and the activation energy of a char in a single experiment, independent of diffusional processes. ${ }^{11)}$ The reactivity measurements on the chars were performed at temperatures in the range $1023-1223 \mathrm{~K}$, and $\mathrm{CO}_{2}$ pressures of $0.5-1 \mathrm{~atm}$. The rate measurements were described by an equation of the form,

$$
r=a \exp [-E /(R T)] p_{\mathrm{CO}_{2}}^{n} \cdots
$$

where $a, n$ and $E$ are measured rate parameters for each particular char. Using this equation the specific reaction rates were then predicted for $1673 \mathrm{~K}$ and a $\mathrm{CO}_{2}$ partial pressure of $0.038 \mathrm{~atm}$ for each of the char types; this $\mathrm{CO}_{2}$ partial pressure in equilibrium with solid carbon at $1673 \mathrm{~K}$. An averaged reaction order, $n$, of 0.6 with respect to $\mathrm{CO}_{2}$ partial pressure was assumed. The reaction order of $0.6 \pm 10 \%$ was typical of chars measured by this technique. ${ }^{12)}$ These predicted rates are listed for the different chars in Table 1; also included in Table 1 are the intrinsic reaction rates for these chars calculated using surface areas determined using $\mathrm{N}_{2}$ BET adsorption. The activation energies of the chars were within the range of $180-230 \mathrm{~kJ} / \mathrm{mol}$. These values correlate reasonably well with other reported activation energies for impure carbons (190-210 kJ/mol). ${ }^{13)}$ The predicted specific chemical reaction rates of the chars in $\mathrm{CO}_{2}$ vary by more than an order of magnitude. In addition previous studies have shown that the reaction rates on coal chars are significantly greater than on graphite surfaces. ${ }^{14)}$

Despite the significant differences in carbon reactivity (see Table 1) the overall rates of reduction of the slags by the various chars are similar within experimental uncertainty (Fig. 3). The exception to this is char 20. Despite the fact that char 20 exhibits the lowest $\mathrm{CO}_{2}$ reactivity, the rate of reduction with this coal char approaches that of graphite and coke. Char 20 is derived from anthracitic coal, whereas the remainder of the chars tested are made from bituminous black coals. Inspection of the reaction rate vs time plots obtained for these various chars shows that despite some variability in behaviour with this material, in general, the rate maxima (peaks in the MS rate vs. time plots) with char 20 are observed to occur at relatively early in the reduction and at high frequency compared to the other chars. This suggests that liquid $\mathrm{Fe}-\mathrm{C}$ drops are formed at the char/slag interface.

The present investigation has shown that both graphite and coke, which have low reactivities in $\mathrm{CO}_{2}$, provide the fastest reduction rates of $\mathrm{FeO}$ from slag at all temperatures. It is now clear that these high reduction rates are due to the preferential formation of liquid $\mathrm{Fe}-\mathrm{C}$ droplets, the fast chemical reaction rates associated with the $\mathrm{CO}_{2}$ gasification of the $\mathrm{Fe}-\mathrm{C}$ alloy, and the mixing of the slag associated with the movement of gas bubbles generated at these $\mathrm{Fe}-\mathrm{C}$ droplets.

In contrast, in the bituminous coal chars the generation of $\mathrm{CO}$ occurs principally through the gasification of solid carbon. As a result, in the reaction geometries investigated in the present study, the slag is not mixed by the resultant product gas and the rates become limited by mass transfer in the slag phase. This conclusion is consistent with the findings obtained using a rotating carbon disk, ${ }^{15)}$ which demonstrated that even at high $\mathrm{FeO}$ concentrations mass transfer in the slag can become rate limiting. In the case of char 20 there is also a significant contribution to the overall reaction from the formation of liquid $\mathrm{Fe}-\mathrm{C}$ droplets at the reaction interface, leading to faster reaction rates.

It should be pointed out that the relative rates of reduction using graphite and coal chars reported in the present study apply to the particular reaction geometry used, i.e. the sessile drop, in which there are significant differences between the apparent contact area between the carbon types. It would be instructive to undertake experiments with various carbons of fixed geometry immersed in slag, as undertaken previously for coke, ${ }^{16)}$ to compare the outcomes.

\section{Conclusions}

The rates of reduction of $\mathrm{FeO}-\mathrm{CaO}-\mathrm{Al}_{2} \mathrm{O}_{3}-\mathrm{SiO}_{2}$ slags by graphite, coke and coal chars have been investigated. It has been shown that the following factors are important in determining to the rates of reduction of $\mathrm{FeO}$-containing slags with carbon,

- Carbon type,

- FeO concentration of the slag,

- Temperature,

- The amount of iron present at the reaction interface,

- The reaction mechanisms that are operative,

- Ash sintering and melting characteristics.

The present studies also show that, for the reaction geometries studied, the overall rates of reduction of iron oxide from slags are faster with graphite and coke than with coal chars, despite the fact that the reactivities of graphite and coke in $\mathrm{CO}_{2}$ are significantly lower than coal chars. The high reaction rates observed with the use of graphite and coke appear to be associated with the formation of liquid $\mathrm{Fe}-\mathrm{C}$ droplets at the slag/carbon interface and the gasification of carbon from the $\mathrm{Fe}-\mathrm{C}$ surface. The overall rates of the graphite/slag reaction are accelerated by increased quantities of iron at the interface, and the consequent stirring of the melt by the product gas bubbles moving through the slag. 
The reactions between slag and char appear to take place through a gas ferrying mechanism at the slag/char interface, the gasification of carbon taking place predominantly at the char surface. The rates of reduction with chars appear to be limited by mass transfer in the slag phase.

\section{Acknowledgements}

The authors would like to extend their thanks to Carbon Consulting International (CCI), the Australian Research Council, and the Australian Commonwealth Government for providing an Australian Postgraduate Award for Industry (APAI), and the Cooperative Research Centre for Black Coal Utilisation (CRC-BCU) for additional financial support for this project.

\section{REFERENCES}

1) S. L. Teasdale and P. C. Hayes: ISIJ Int., 45 (2005), 634

2) S. L. Teasdale: Ph.D. Thesis, University of Queensland, Brisbane,
Australia (2000)

3) F. S. Feates and C. W. Keep: Trans. Faraday Soc., 66 (1970), 3156

4) A. A. Lizzio, H. Jiang and L. R. Radovic: Carbon, 28 (1990), 7.

5) T. C. Brown and B. S. Haynes: Energy Fuels, 6 (1992), 154.

6) S. R. Kelemen and H. Freund: Carbon, 23 (1985), 619.

7) P. L. Walker, R. L. Taylor and J. M. Ranish: Carbon, 29 (1991), 411.

8) F. Kapteijn, R. Meijer, B. v. Eck and J. A. Moulijn: Fundamental Issues in Control of Carbon Gasification Reactivity, ed. by J. Lahaye and P. Ehrburger, Kluwer Academic, New York, (1991), 221.

9) F. Kapteijn, R. Meijer, J. A. Moulijn and D. Cazorla-Amoros: Carbon, 32 (1994), 1223.

10) D. R. Sain and G. R. Belton: Metall. Trans. B, 7B (1976), 235

11) D. J. Harris and I. W. Smith: Am. Chem. Soc. Div. Fuel Chem. Prepr., 34 (1989), 94.

12) D. J. Harris and I. W. Smith: 23rd Int. Symp. on Combustion, The Combustion Institute, Pittsburgh, PA, (1990), 1185.

13) K. Muira, K. Hashimoto and P. Silveston: Fuel, 68 (1989), 1461

14) S. Dutta, C. Y. Wen and R. J. Belt: Ind. Eng. Chem. Process Des. Dev., 16 (1977), 20.

15) J. Mroz: Metall. Mater. Trans. B, 32B (2001), 821.

16) J. Mroz: Scand. J. Metall., 16 (1987), 16. 